\title{
Tensile properties of in-situ precipitated polydimethylsiloxane networks
}

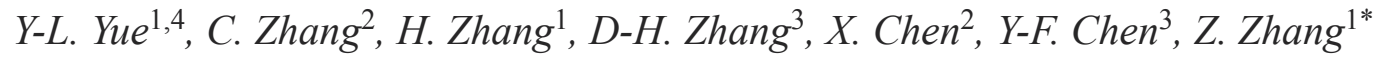 \\ ${ }^{1}$ National Center for Nanoscience and Technology, 100190 Beijing, China \\ ${ }^{2}$ State Grid Smart Grid Research Institute, 102211 Beijing, China \\ ${ }^{3}$ Institute of Process Engineering, Chinese Academy of Sciences, 100190 Beijing, China \\ ${ }^{4}$ University of Chinese Academy of Sciences, 100049 Beijing, China
}

Received 8 May 2013; accepted in revised form 26 June 2013

\begin{abstract}
Tensile propertiesof polydimethylsiloxane (PDMS) networks filled with in-situ precipitated silica were investigated. Experimental results showed that increasing the swelling time of cured rubber sheets in tetraethoxysilane (TEOS) solution or elevating the humidity and temperature of precipitation reaction atmosphere can render to a positive reinforcing effect. Moreover the in-situ precipitation method can be used to further enhance the tensile properties of fumed silica filled PDMS networks. The reinforcement introduced by the in-situ precipitated silica gel particles can probably be attributed to the adsorption of polymer chains onto silica surface, the pinning effect of polymer chains within gel particles, and the fillerfiller gel structure among gel particles.
\end{abstract}

Keywords: rubber, polymer composites, reinforcements, mechanical properties

\section{Introduction}

The sol-gel method is generally used to prepare polymer-matrix composites (PMCs) using pure ceramic precursors at relatively low temperatures [1-3]. In 1982, Mark and Pan [4] firstly introduced this method to in-situ precipitate silica within PDMS networks. The in-situ precipitation reaction can be roughly divided into two steps: hydrolysis of alkoxylsilicates to produce hydroxyl groups, followed by polycondensation of the hydroxyl groups and residual alkoxyl groups to form a three-dimensional gel network. The reactions typically proceed with either an acid or a base as catalyst to accelerate the reaction rate [5].Thus, the total precipitation reaction using typical TEOScan be described as:

$$
\left(\mathrm{C}_{2} \mathrm{H}_{5} \mathrm{O}\right)_{4} \mathrm{Si}+2 \mathrm{H}_{2} \mathrm{O} \stackrel{\mathrm{H}^{+}, \mathrm{OH}^{-}}{\longrightarrow} \mathrm{SiO}_{2}+4 \mathrm{C}_{2} \mathrm{H}_{5} \mathrm{OH}
$$

which consists of hydrolysis:

$$
\mathrm{Si}-\mathrm{O}-\mathrm{C}_{2} \mathrm{H}_{5}+\mathrm{H}_{2} \mathrm{O} \stackrel{\mathrm{H}^{+}, \mathrm{OH}^{-}}{\longrightarrow} \mathrm{Si}-\mathrm{OH}+\mathrm{C}_{2} \mathrm{H}_{5} \mathrm{OH} \text {, }
$$

and polycondensation:

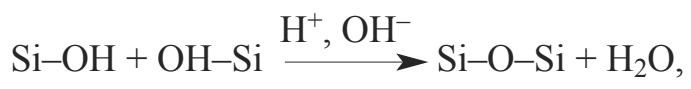

or,

$$
\mathrm{Si}-\mathrm{O}-\mathrm{C}_{2} \mathrm{H}_{5}+\mathrm{OH}-\mathrm{Si} \stackrel{\mathrm{H}^{+}, \mathrm{OH}^{-}}{\longrightarrow} \mathrm{Si}-\mathrm{O}-\mathrm{Si}+\mathrm{C}_{2} \mathrm{H}_{5} \mathrm{OH} \text {. }
$$

The precipitation process consists of hydrolysis, polycondensation (including nucleation, growth and aggregation), gelation, aging (including polymerization, coarsening and syneresis) and drying (including evaporation and densification), which has been

\footnotetext{
${ }^{*}$ Corresponding author, e-mail: zhong.zhang@nanoctr.cn

(C) BME-PT
} 
overall reviewed by Brinker [6]. Different kinds of catalyst have dramatic effect on the precipitation process and on the final gel structure [7, 8]. Experimental results [9] have shown that acid catalyzed reactions tend to produce more chain-like polymeric entities while basic environments tend to produce more highly condensed and discrete particulate structures. Herein, we pay more attention to the acid-catalyzed precipitation process because only acid catalyst is adopted in our experiments. Acidcatalyzed hydrolysis occurs by the nucleophilic attack of the oxygen contained in water molecules on the silicon atoms and acid-catalyzed condensation involves the protonation of silanol species, which makes the silicon more electrophilic and more susceptible to nucleophilic attack [6].

Many literatures [10-15] have reported that in-situ precipitated networks show much improved mechanical properties compared with pure networks. Further researches [16-19] demonstrated that, compared with the agglomerated fumed silica particles incorporated by mechanical blending, in-situ precipitated silica gel particles are more homogeneously dispersed within the networks, thanks to the molecular-level dispersion of precursors. Also, the gel particles are generally in the nanoscale length with very narrow size distribution. Fragiadakis and coworkers [20-22] have studied the chain dynamics by various techniques. They found an interfacial structure with reduced segmental mobility between gel particles and polymer matrix. Hernandez et al. [23] have proven that the formation of continuous silica phase (or filler network) above the percolation concentration can also have an influence on the dynamic mechanical modulus of composites.

Although the in-situ precipitation method has been developed for decades, the mechanisms of reinforcement caused by the gel particles have not yet been completely clarified. The objective of the current work is to explore the reinforcing mechanisms and investigate the effect of different precipitation conditions on the tensile properties.

\section{Experimental section}

\subsection{Materials}

The $\alpha, \omega$-hydroxylated PDMS with average molecular weight of $80300 \mathrm{~g} / \mathrm{mol}$ and polydispersity index of 1.35 was purchased from WACKER (Germany). The fumed silica with a trademark of R106 was provided by Evonik Degussa (Germany), which has been partially surface-modified from pristine fumed silica A300 using octamethylcyclotetrasiloxane $\left(D_{4}\right)$. The tetra-functional cross-linker tetraethoxysilane (TEOS) and catalyst dibutyltin dilaurate (DBTDL) were supplied by Tian Jin Bodi Corporation (China).The toluene (A.R.) was obtained from Beijing Chemical Works (China). All materials were used as received without further treatment.

\subsection{Preparation of filled networks}

Fumed silica was mechanically blended with PDMS on a three-roll mill (EXAKT80E, Germany). After addition of TEOS and DBTDL, the pure PDMS and R106/PDMS suspensions were vulcanized at room temperature using solution curing method. More detailed process can be referred to our previous work [24].

The in-situ precipitated networks were prepared by immersing cured rubber sheets into TEOS solution containing $3 \mathrm{wt} \%$ of DBTDL for various time, as depicted in the work of Dewimille et al. [17]. The swollen sheets were laid at labs with normal conditions (temperature of $23 \pm 2^{\circ} \mathrm{C}$ and relative humidity of $50 \pm 20 \%$ ) or within the constant temperature and humidity chamber (EYELAKCL-2000, Japan) to react for $24 \mathrm{~h}$ and then placed in an oven at $80^{\circ} \mathrm{C}$ until constant weights reached. Water molecular for hydrolysis reaction was obtained from water vapor in the atmosphere. DBTDL can generate lauric acid by hydrolysis, which acts as the catalyst for the hydrolysis and condensation reactions of TEOS. The amounts of silica in-situ precipitated within the networks were calculated from the sheet weights before and after precipitation. The reaction conditions and concentrations were listed in Table 1.

\subsection{Tensile tests}

The samples for tensile tests were stamped out from rubber sheets (with a thickness of ca. $2 \mathrm{~mm}$ ) using a dumbbell-shaped cutter (with a $4 \mathrm{~mm}$ width and $20 \mathrm{~mm}$ initial gauge length). The tests were performed at room temperature on a tensile testing machine CMT-4104 (SANS, China) at a crosshead rate of $50 \mathrm{~mm} / \mathrm{min}$. At least five specimens were tested for each sample. The ultimate tensile strength $\left(f_{\mathrm{m}}^{*}\right)$ and break elongation $\left(\alpha_{\mathrm{m}}\right)$ can be directly obtained from stress-strain $\left(f^{*}-\alpha\right)$ curves. The area under the stress-strain curve corresponds to the network breakup energy $\left(E_{\mathrm{b}}\right)$, which can be used as a measure of material toughness [25]. Meanwhile, 
elastic modulus or reduced stress can be obtained from the well-known Mooney-Rivlin equation (Equation (1)):

$\left[f^{*}\right]=2 C_{1}+2 C_{2} \alpha^{-1}$

where constant $2 C_{1}$ is taken as the limit modulus of a phantom network and $2 C_{2}$ is regarded as a measure of the extent of non-affine deformation [26, 27].

\subsection{Characterization}

Equilibrium swelling method was adopted to evaluate the cross-linking degree of networks. Pieces of measured weights of vulcanized rubber sheets $\left(m_{1}\right)$ were immersed in toluene for $72 \mathrm{~h}$ at room temperature. Then the swollen sheets were wiped gently with a filter paper to remove unabsorbed solvent and their weights were measured as $m_{2}$. The amount of absorbed toluene can be determined by the weight difference before and after swelling $\left(m_{2}-m_{1}\right)$. Herein, the equilibrium swelling ratio $\left(q_{\text {es }}\right)$ was employed to reflect the degree of cross-linking, which is simply defined as the mass ratio of the absorbed solvent to the pure rubber (Equation (2)):

$q_{\mathrm{es}}=\frac{m_{2}-m_{1}}{m_{1}(1-\phi)}$

where $\phi$ is the mass fraction of filler.

Small-angle X-ray scattering (SAXS) is widely used to provide averaged statistical information of multi-phase composites having phase structures in the nanoscale [17, 28, 29]. 2D SAXS patterns were collected within $100 \mathrm{~s}$ at room temperature on the beamline BL16B1 in Shanghai Synchrotron Radiation Facility (SSRF) in China. The wavelength was $0.154 \mathrm{~nm}$ and the sample-to-detector distance was $5110 \mathrm{~mm}$. The thickness of testing specimens was about $0.5 \mathrm{~mm}$. One dimensional scattering intensity curves $(I(q)$ vs. $q)$ were obtained by radial average method using FIT2D program [30]. The data were calibrated by pure rubber sheet and normalized with respect to the incoming beam intensity.

The fractured cross-sectional surface of filled networks was examined by an atomic force microscope (AFM, Multimode 8, Bruker, Germany) in the tapping mode at the frequency of $1 \mathrm{~Hz}$.

\section{Results and discussion \\ 3.1. Effect of swelling time on tensile properties}

As shown in Figure 1, the swelling rate of pure rubber sheet in TEOS solution decreases with time according to a power law. The swelling ratio, defined as the mass ratio of the solution to the pure rubber, increases sharply at the initial stage and slows down gradually until an equilibrium swelling state reached. Thus, networks filled with various loadings of precipitated silica can be obtained by changing the swelling time.

Tensile properties of networks filled with various concentrations of silica gel particles precipitated at normal conditions were presented in Figure 2 and listed in Table 1. It can be seen that the modulus, tensile strength, break elongation and network breakup energy all increase with filler concentration. Compared with pure network, all filled networks exhibit non-Gaussian effect, i.e. the anomalous upturn in modulus plots. Meanwhile, the non-Gaussian effect emerges at a lower strain as concentration increases, suggesting the existence of more and shorter segments within the filled networks. Moreover, the upturn becomes suppressed at large strains for concentrations above $9.04 \mathrm{wt} \%$ and it nearly vanishes for the extremely high concentration of $17.26 \mathrm{wt} \%$. It is beneficial to compare the in-situ precipitated networks with the fumed silica filled networks to explore the reinforcing mechanisms. In our previous work [24], we have discussed the tensile properties of fumed silica filled PDMS networks in detail. Therein, the reinforcement was attributed to

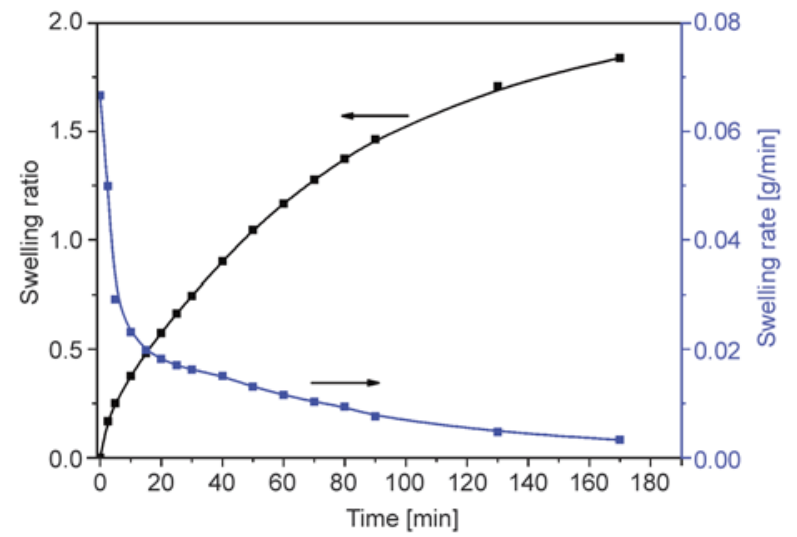

Figure 1. Swelling ratio and swelling rate of pure PDMS in TEOS solution as a function of time 

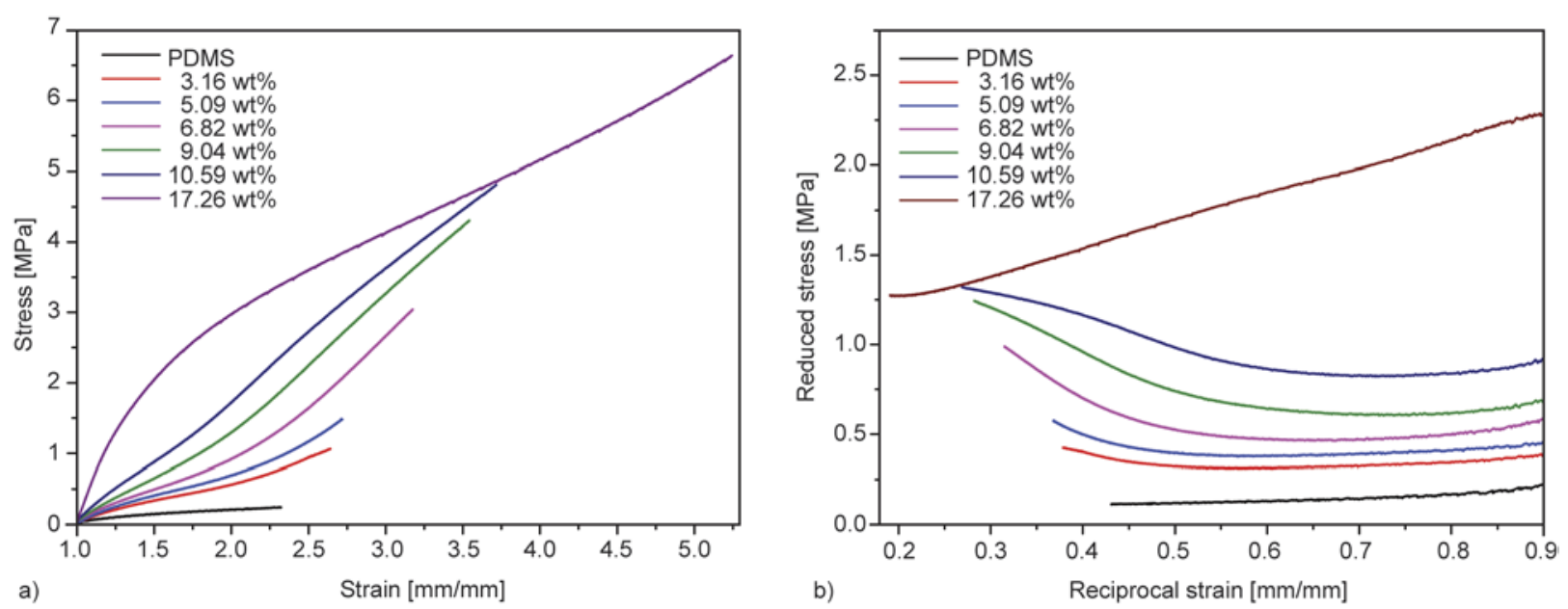

Figure 2. Stress-strain curves (a) and Mooney-Rivlin plots (b) for networks filled with various concentrations of in-situ precipitated silica

Table 1. Tensile testing results and equilibrium swelling ratio for unfilled and filled networks

\begin{tabular}{|l|c|c|c|c|}
\hline $\begin{array}{c}\text { Samples } \\
\text { (Concentrations) }\end{array}$ & $\begin{array}{c}\mathbf{f}_{\mathbf{m}}{ }^{*} \\
{[\mathbf{M P a}]}\end{array}$ & $\begin{array}{c}\boldsymbol{\alpha}_{\mathbf{m}} \\
{[\mathbf{\%}]}\end{array}$ & $\begin{array}{c}\mathbf{E}_{\mathbf{b}} \\
{\left[\mathbf{J} / \mathbf{m m}^{3}\right]}\end{array}$ & $\mathbf{q}_{\text {es }}$ \\
\hline PDMS & $0.25 \pm 0.02$ & $141 \pm 9$ & $0.21 \pm 0.02$ & 3.35 \\
\hline $3.16 \mathrm{wt} \%$ & $0.97 \pm 0.12$ & $164 \pm 10$ & $0.83 \pm 0.03$ & 2.29 \\
\hline $5.09 \mathrm{wt} \%$ & $1.47 \pm 0.11$ & $176 \pm 12$ & $1.12 \pm 0.05$ & 2.24 \\
\hline $6.82 \mathrm{wt} \%$ & $3.05 \pm 0.08$ & $217 \pm 4$ & $2.68 \pm 0.01$ & 2.18 \\
\hline $9.04 \mathrm{wt} \%$ & $4.31 \pm 0.08$ & $255 \pm 2$ & $4.97 \pm 0.01$ & 2.05 \\
\hline $10.59 \mathrm{wt} \%$ & $4.93 \pm 0.10$ & $287 \pm 13$ & $6.62 \pm 0.05$ & 2.95 \\
\hline $17.26 \mathrm{wt} \%$ & $6.41 \pm 0.45$ & $398 \pm 15$ & $17.40 \pm 0.08$ & 2.21 \\
\hline $25^{\circ} \mathrm{C}-40 \%(3.82 \mathrm{wt} \%)$ & $2.20 \pm 0.12$ & $216 \pm 9$ & $1.82 \pm 0.03$ & 2.24 \\
\hline $25^{\circ} \mathrm{C}-60 \%(5.32 \mathrm{wt} \%)$ & $2.76 \pm 0.13$ & $230 \pm 13$ & $2.72 \pm 0.05$ & 2.30 \\
\hline $25^{\circ} \mathrm{C}-80 \%(6.43 \mathrm{wt} \%)$ & $3.43 \pm 0.12$ & $260 \pm 8$ & $3.70 \pm 0.04$ & 1.87 \\
\hline $20^{\circ} \mathrm{C}-60 \%(4.33 \mathrm{wt} \%)$ & $2.01 \pm 0.11$ & $207 \pm 14$ & $1.74 \pm 0.05$ & \\
\hline $30^{\circ} \mathrm{C}-60 \%(6.03 \mathrm{wt} \%)$ & $3.40 \pm 0.22$ & $252 \pm 15$ & $4.10 \pm 0.06$ & \\
\hline
\end{tabular}

both the effective volume effect originated from filler volume and polymer-filler interaction and the synergistic effect between network chains of different length scales within the 'hierarchical network'. The 'hierarchical network' sets a stage for the shorter network chains or segments to exhibit non-Gaussian behavior at lower strains and for the networks to show non-Gaussian effect, just as the case in bimodal networks [25, 31, 32]. Herein, the polymer-filler interaction within the interfacial structure includes a new interaction type of 'pinning effect' within gel particles, in addition to the adsorption effect caused by hydrogen bond and van der Waals forces on the gel particle surface. Specifically, a certain number of PDMS chains can be trapped and pinned up during the formation of silica gel particles, thanks to the excellent compatibility between organic and inorganic components. The pinning effect can behave, to some extent, like chemical cross-links because generally, the rupture of chemical bonds is needed to remove the pinning effect. Consequently, the force of overcoming pinning effect is obviously much larger than the desorption force. This is part of the reason why in-situ precipitated networks exhibit better mechanical properties than fumed silica filled networks at the same filler concentration [10].The pinning and adsorption divide network chains into shorter segments in a great larger number, thus increase the degree of cross-linking density. McCarthy et al. [33] found that no non-Gaussian effect was observed in polymethylphenylsiloxane (PMPS) networks in-situ precipitated with titania, which is probably due to the very weak polymerfiller interaction including no pinning and adsorption effect. On the other hand, unlike fumed silica particles tend to form agglomerates (especially at high filler loadings), in-situ precipitated gel particles are well dispersed within the networks. This can be inferred from SAXS plots in Figure 3, where fumed silica filled networks only show a strong shoulder at low scattering vectors while precipitated networks show a rather weak peak within the 

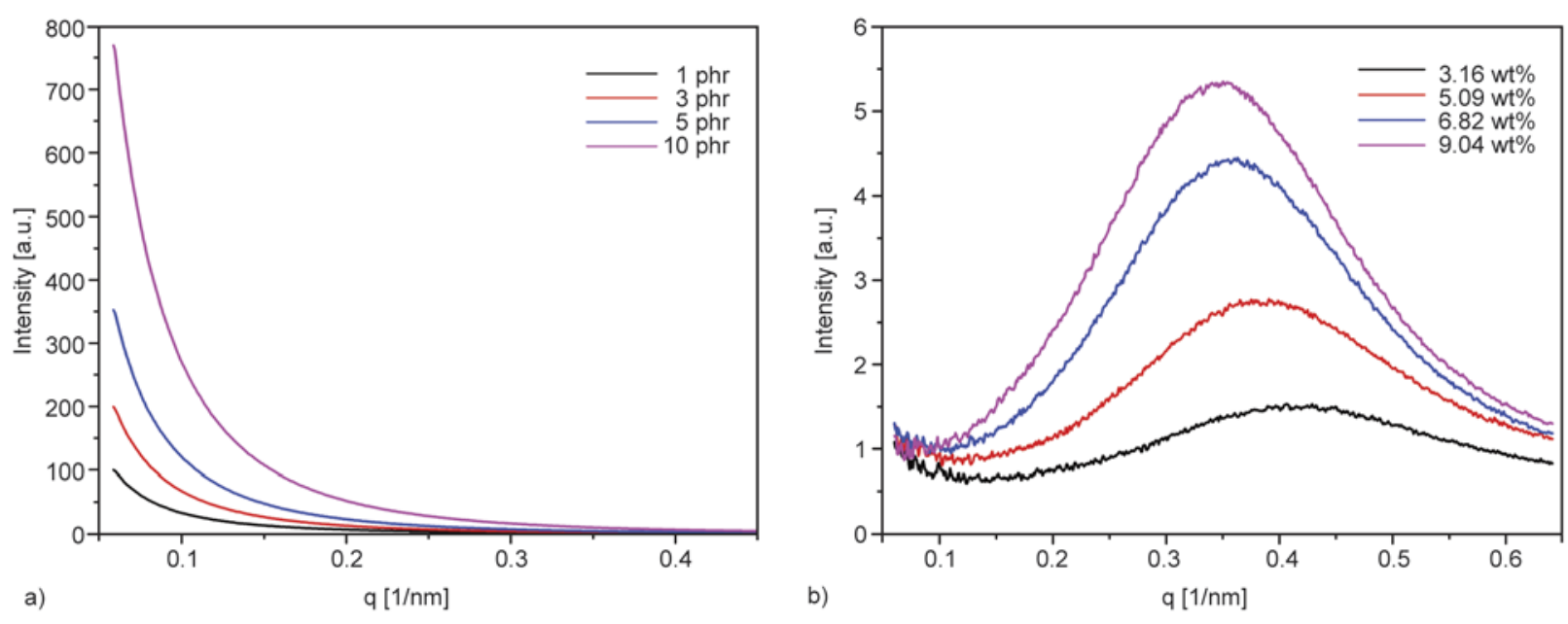

Figure 3. SAXS plots of networks filled with various concentrations of: (a) fumed silica R106, (b) in-situ precipitated silica

range of $0.2-0.51 / \mathrm{nm}$. These peaks can be attributed to the relative scattering between well dispersed gel particles. Besides, the fractal dimension of scattering entities calculated from the SAXS plots using program PRIMUS [34] increases from 1.78 to 3.10 , suggesting that the gel structure become more and more condensed as filler concentration increases. The increase of these scattering peaks is a combined effect of the increase in the number, size and condensed structure of gel particles. This is different from the case of fumed silica filled networks, where the increase of scattering peak is caused only by the increase of particle number. Due to the strong polymer-filler interaction and well dispersed nanoparticles, the percolation concentration of precipitated silica for the formation of 'hierarchical network' structure is expected be much lower than that of fumed silica (2-3 phr for R106 filled networks [24]).

Therefore, the stress-strain behaviors of in-situ precipitated networks can be explained. The augmented modulus in the linear regime can still be attributed to the filler's effective volume effect including the increase of both filler volume and cross-linking density (caused by adsorption and pinning effect). The increase of cross-linking density can be confirmed by the decrease of equilibrium swelling ratio as listed in Table 1 . The upturn of modulus at large strains can be attributed to the synergistic effect between network chains of different length scales within the 'hierarchical network' generated by gel particles. The suppression of modulus upturn at very large strains for highly precipitated networks can be interpreted by the breakup of bridging gel structure. The bridging gel structure between

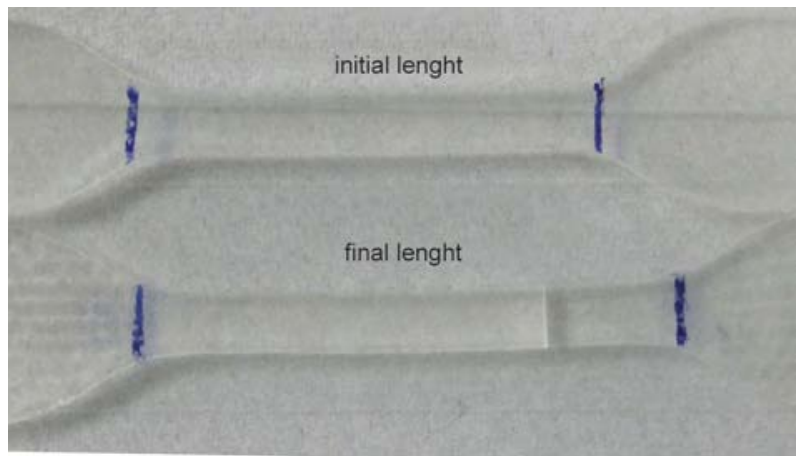

Figure 4. Photo image of the sample before and after tensile tests at the concentration of $9.04 \%$

gel particles can be directly seen on the transmission electron microscope (TEM) graph in the work of Dewimille et al. [17]. This interpretation can further be adopted to explain the decrease of modulus for the network precipitated with $17.26 \mathrm{wt} \%$ of gel particles, where the gel filler network makes the dominant contribution to the mechanical properties. The deformation and breakup of gel structure is some sort of irreversible plastic deformation, which can be confirmed by the apparent residual strain (or, permanent set) as shown in Figure 4 and be observed from the 3D AFM height graphs in Figure 5. Only sparse valleys were seen on the fractured cross-sectional surface of fumed silica filled network, while dense peaks and dips were observed on the surface of in-situ precipitated network.

\subsection{Effect of humidity and temperatureon tensile properties}

The reaction conditions have a huge influence on the dynamics of hydrolysis and polycondensation reaction and on the structure of formed silica gel particles $[6,7,35]$. Consequently, the precipitated 

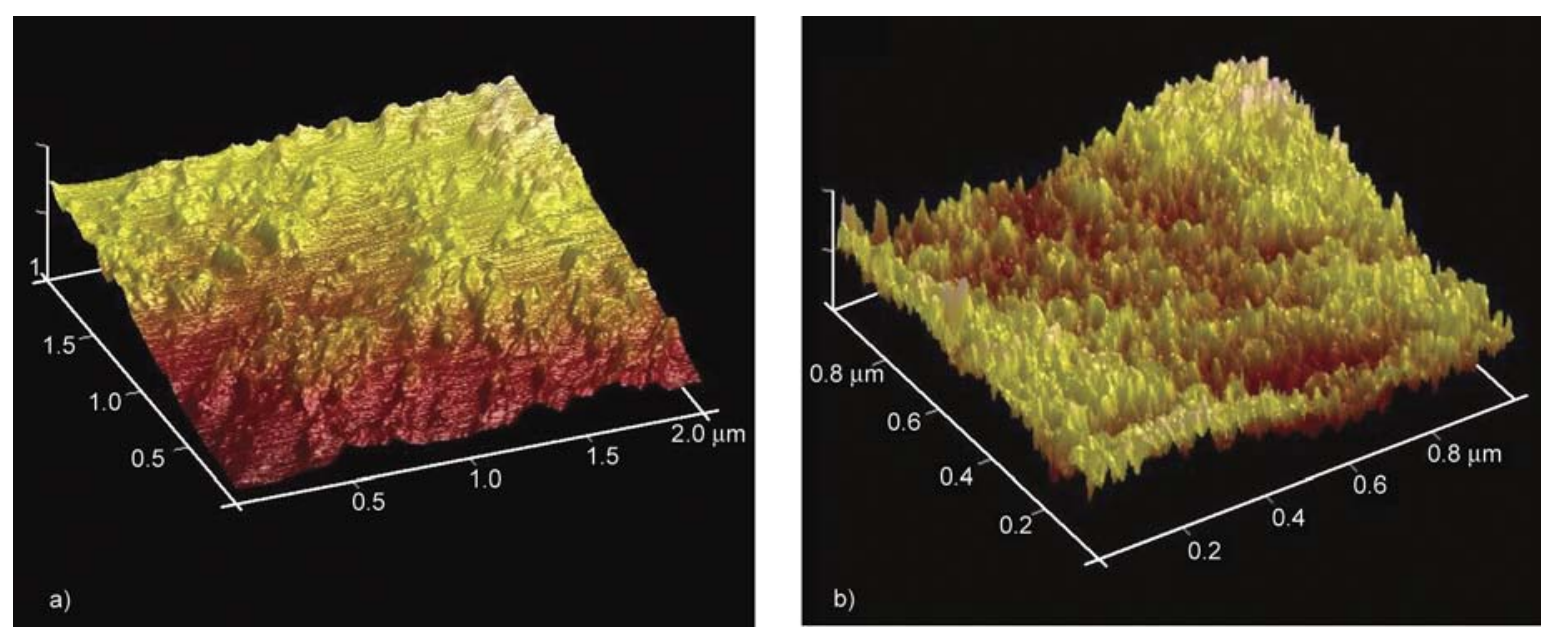

Figure 5. 3D AFM height graphs of fractured cross-sectional surface for networks filled with: (a) 10 phr of fumed silica R106, (b) $9.04 \%$ of in-situ precipitated silica

networks prepared under different conditions can exhibit various mechanical properties. Herein, we mainly study on the effect of humidity and temperature on the tensile properties of in-situ precipitated networks. Experimental results in the first column of Table 1 show that the concentration of silica gel particles within the networks (swelled in TEOS solution for 30 minutes) increases with both humidity and temperature, suggesting the higher transformation efficiency of TEOS to silica gel. Again, the structure of gel particles can be examined from SAXS plots in Figure 6. The increase of scattering peaks can again be regarded as the combined effect of the increase in the number, size and condensed structure of gel particles.

From Figure 7 and Table 1, it is seen that all mechanical parameters increase with the humidity and temperature. Meanwhile, the upturn of modulus occurs at a lower strain, suggesting the existence of more and shorter segments within the networks. The humidity provides water molecular for the hydrolysis of both TEOS and DBTDL. Thus, the most obvious effect of increased humidity is the promotion of hydrolysis [36]. Brinker et al. [37] found that when hydrolysis is fast, higher density coarse textured gel particles are formed, otherwise, less low density fine textured gel particles are formed. This can be confirmed by the SAXS curves in Figure 6a. The elevated temperature has an influence on the whole precipitation process, such as accelerating the dynamics of hydrolysis and polycondensation, increasing the gelation rate, shortening the periods of aging and drying, etc. As a result, more high density coarse textured gel particles form at higher temperatures, as demonstrated by SAXS plots in Figure $6 b$.

To some extent, the raising of humidity and temperature generates the same reinforcing effect as the increase of swelling time. Therefore, the reinforcing mechanisms can be analyzed from the aspects
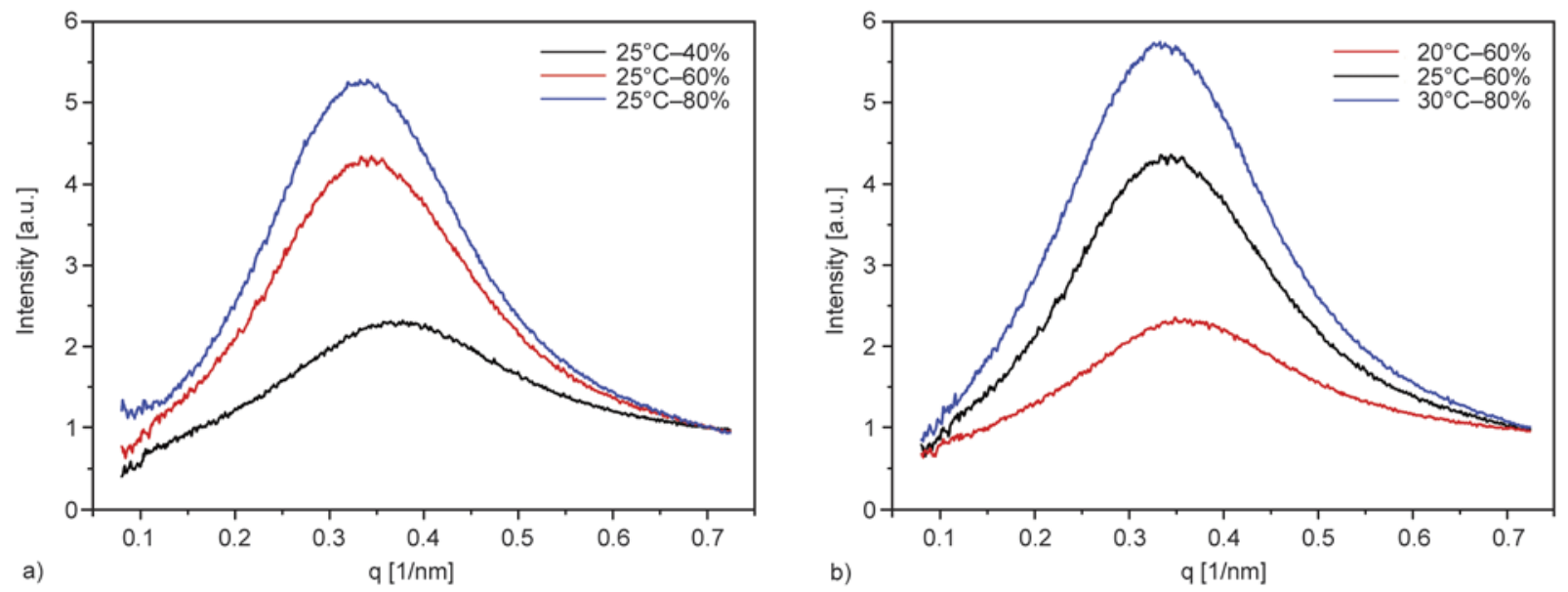

Figure 6. SAXS plots of networks filled with in-situ precipitated silica at variant humidities (a) and temperatures (b) 


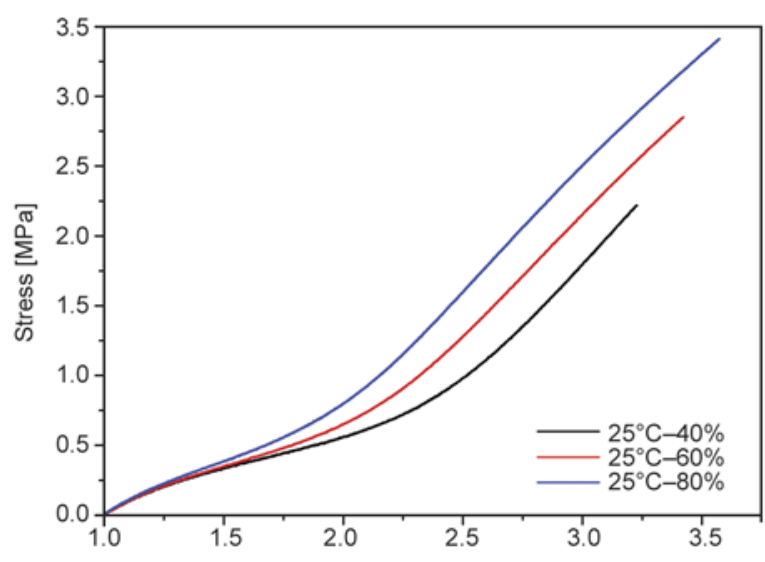

a)

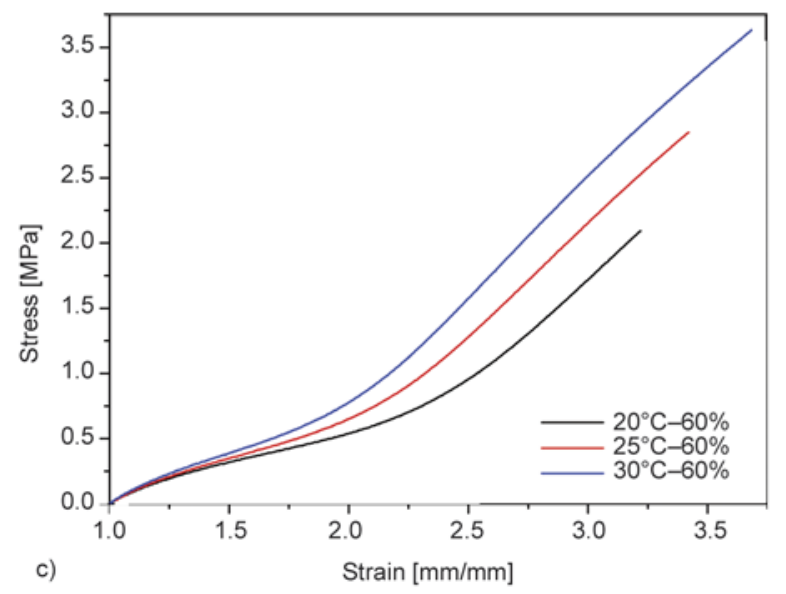

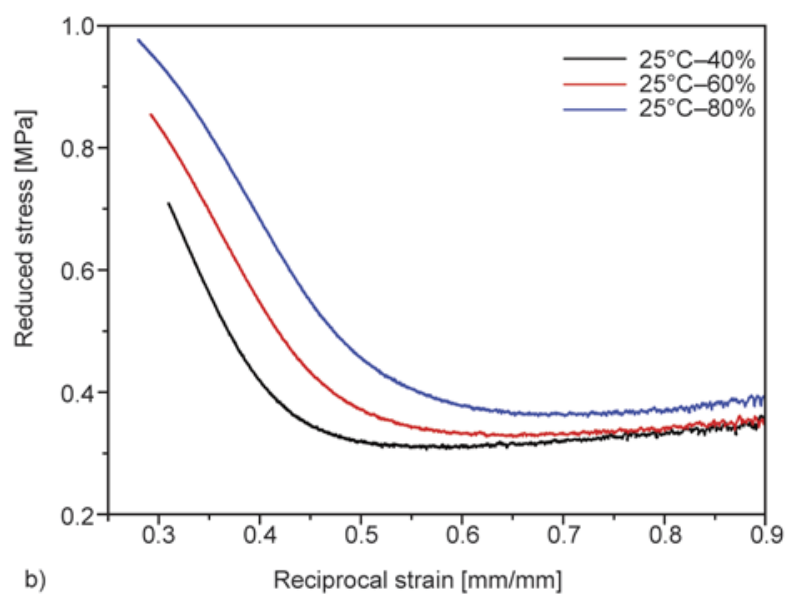

b)

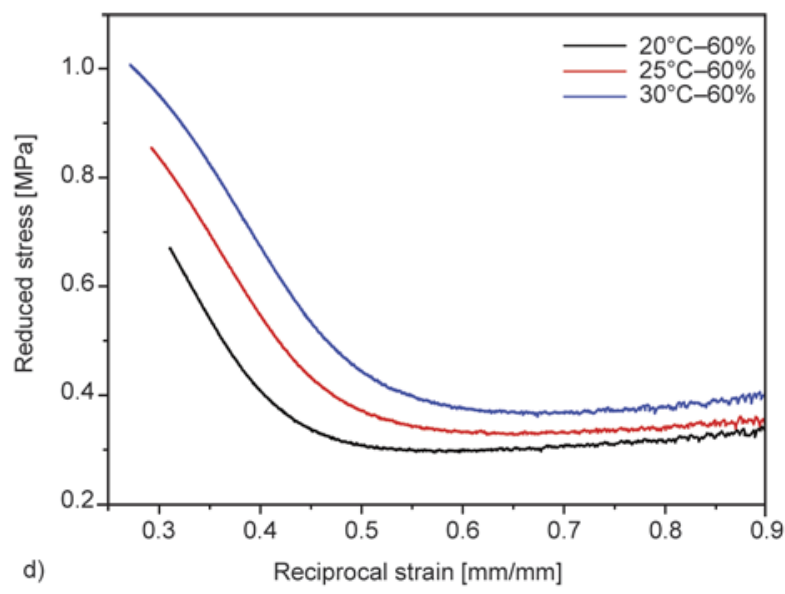

Figure 7. Stress-strain curves (a, c) and Mooney-Rivlin plots (b, d) for networks filled with silica in-situ precipitated at variant humidities and temperatures

of both effective volume effect and synergistic effect similar to the analysis in the above section. In short, the tensile properties of networks precipitated at higher humidity and temperature benefit from more silica gel particles with condensed structure, stronger polymer-filler interaction from pinning and adsorption effect and larger extent of synergistic effect from more and shorter segments.

\subsection{Effect of second reinforcement}

One advantage of in-situ precipitation method is that it can provide a second reinforcement on the filled networks, non-destructively. These secondly filled networks posess much better mechanical properties and have extended service life in extremely harsh applications. Moreover, this method can overcome the shortcomings of blending method involving the poor processability of high-viscosity mixtures caused by adding lots of reinforcing fillers [4]. We firstly conducted a second in-situ precipitation (swell for $30 \mathrm{~min}$, react at $20^{\circ} \mathrm{C}$ and $40 \%$ ) using the precipitated network labeled as ' $25^{\circ} \mathrm{C}-40 \%$ '. The concentration of silica gel particles increases from 3.82 to $5.76 \mathrm{wt} \%$ after the second precipitation. The stress-strain curves and Mooney-Rivlin plots of networks after the first and second precipitation were presented in Figure 8. It can be seen that the tensile strength increases from 2.22 to $3.47 \mathrm{MPa}$, break elongation increases from 223 to $241 \%$ and network breakup energy increases from 1.82 to $3.40 \mathrm{~J} / \mathrm{mm}^{3}$. The emergence of non-Gaussian effect of second precipitated network occurs at a lower strain, suggesting that the network chains have been further shortened due to the addition of pinning and adsorption effect. Meanwhile, the equilibrium swelling ratio decreases from 2.21 to 1.97 , confirming that the cross-linking degree of filled networks further increases.

We also conducted a second in-situ precipitation (swell for $5 \mathrm{~min}$, react at normal conditions) on the fumed silica R106 filled networks. The results of tensile tests before and after precipitation were presented in Figure 9. It can be seen that the modulus, tensile strength and network breakup energy increase 

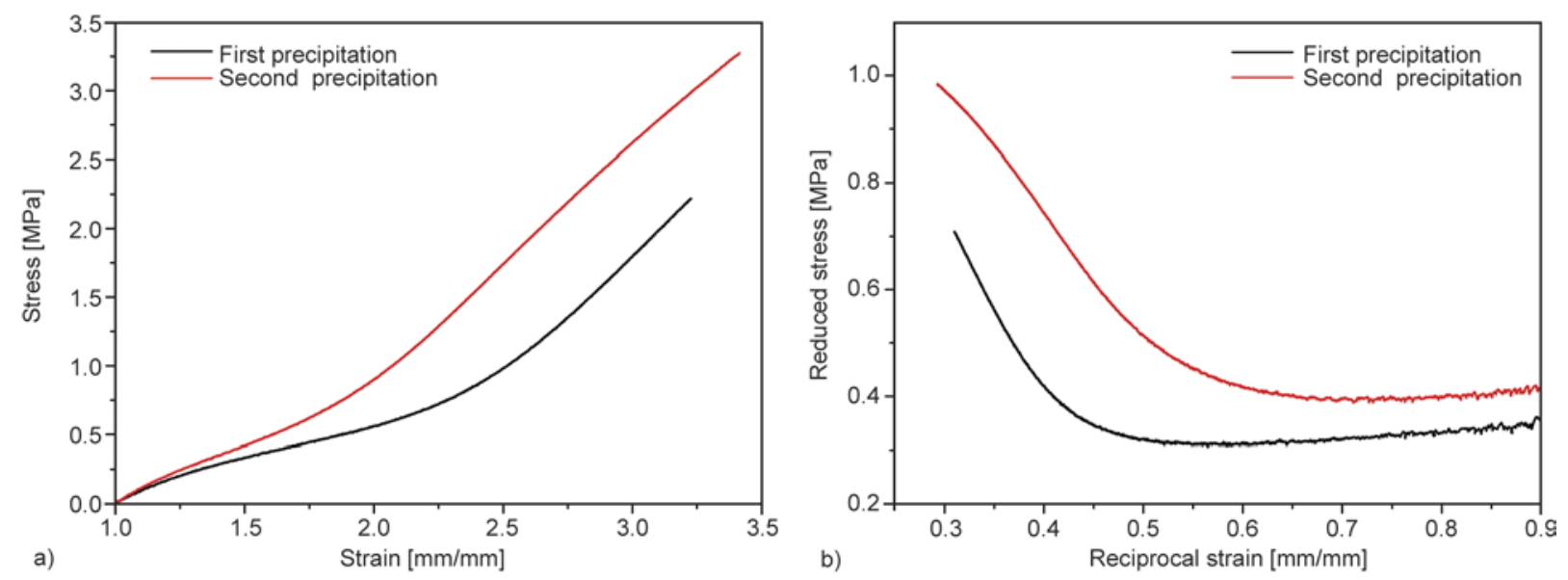

Figure 8. Stress-strain curves (a) and Mooney-Rivlin plots (b) for networks filled with first and second precipitation
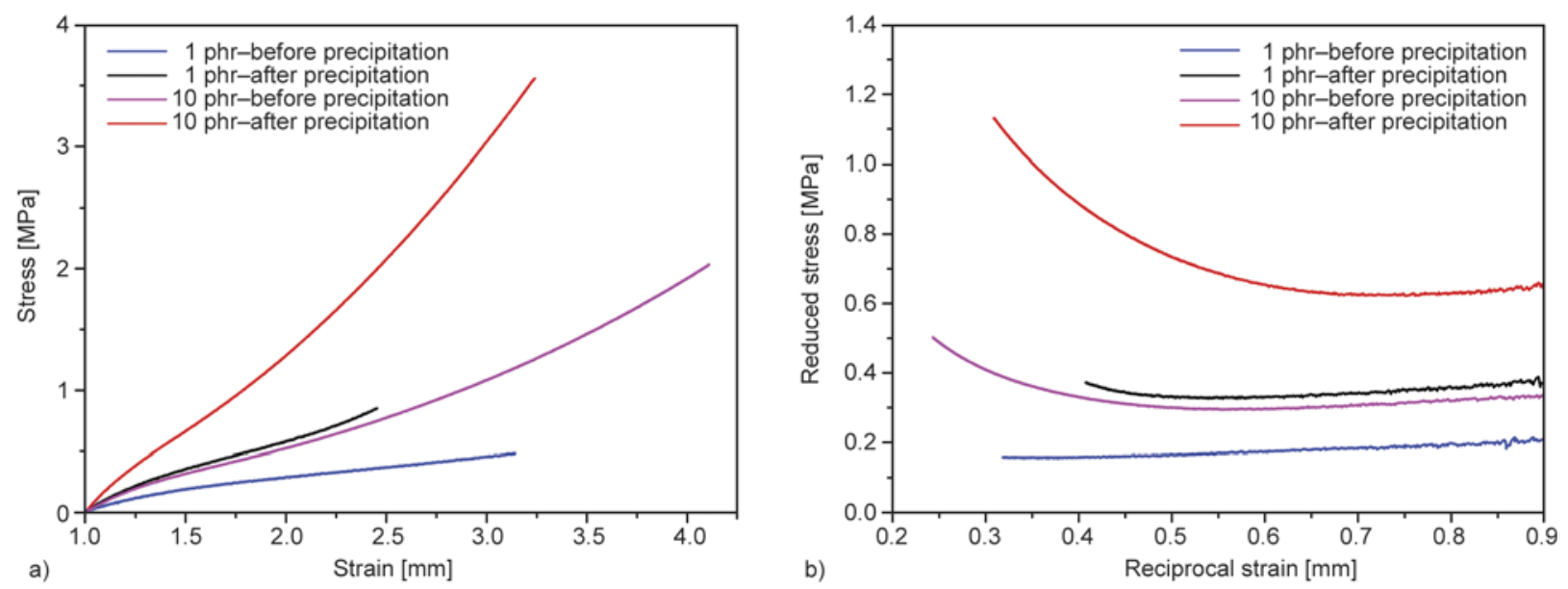

Figure 9. Stress-strain curves (a) and Mooney-Rivlin plots cipitation

after the precipitation, while the break elongation decreases. For network filled with $1 \mathrm{phr}$ of R106, Gaussian effect becomes non-Gaussian after the precipitation, suggesting the formation of the 'hierarchical network' structure; for network filled with $10 \mathrm{phr}$ of R106, non-Gaussian effect occurs at a lower strain after the precipitation, indicating more and shorter network chains form due to the pinning and adsorption effect. The decrease of break elongation seems unexpected and elusive. This phenomenon indicates that there is some kind of incompatibility between fumed silica and silica gel particles within the networks. The two types of particles probably have different influences on the fracture properties of filled networks.

\section{Conclusions}

In-situ precipitation method can be used to improve the mechanical properties of pure and filled polydimethylsiloxane networks. By changing the swelling

time, humidity and temperature, various concentrations of silica gel particles with different structures can be generated within the networks. Due to the polymer-filler interaction, including the adsorption effect on the gel particle surface and the pinning effect within the gel particles, precipitated networks show much improved tensile properties. The bridging gel structures between gel particles also have a positive influence on the mechanical properties, especially at high filler concentrations. More research work is needed to clarify the fracture mechanisms of networks filled by different methods.

\section{Acknowledgements}

This project was jointly supported by a key international collaboration project (Grant No. 2011DFR50200) and the National Key Basic Research Program of China (Grant No. 2012CB937503) of the Ministry of Science and Technology of China, and the National Nature Science Foundation of China (Grant Nos. 11225210 and 51073044), and a research project of State Grid of China (Grant No. DG17201200051). 


\section{References}

[1] Wen J. Y., Wilkes G. L.: Organic/inorganic hybrid network materials by the sol-gel approach. Chemistry of Materials, 8, 1667-1681 (1996).

DOI: $10.1021 / \mathrm{cm} 9601143$

[2] Kickelbick G.: Concepts for the incorporation of inorganic building blocks into organic polymers on a nanoscale. Progress in Polymer Science, 28, 83-114 (2003). DOI: 10.1016/S0079-6700(02)00019-9

[3] Mark J. E.: Some novel polymeric nanocomposites. Accounts of Chemical Research, 39, 881-888 (2006). DOI: 10.1021/ar040062k

[4] Mark J. E., Pan S-J.: Reinforcement of polydimethylsiloxane networks by in-situ precipitation of silica: A new method for preparation of filled elastomers. Die Makromolekulare Chemie, Rapid Communications, 3, 681-685 (1982). DOI: $10.1002 /$ marc. 1982.030031006

[5] Artaki I., Bradley M., Zerda T. W., Jonas J.: NMR and Raman study of the hydrolysis reaction in sol-gel processes. Journal of Physical Chemistry, 89, 43994404 (1985).

DOI: $10.1021 / \mathrm{j} 100266 \mathrm{a} 050$

[6] Brinker C. J.: Hydrolysis and condensation of silicates: Effects on structure. Journal of Non-Crystalline Solids, 100, 31-50 (1988).

DOI: $10.1016 / 0022-3093(88) 90005-1$

[7] Osterholtz F. D., Pohl E. R.: Kinetics of the hydrolysis and condensation of organofunctional alkoxysilanes: A review. Journal of Adhesion Science and Technology, 6, 127-149 (1992). DOI: $10.1163 / 156856192 X 00106$

[8] Pope E. J. A., Mackenzie J. D.: Sol-gel processing of silica: II. The role of the catalyst. Journal of Non-Crystalline Solids, 87, 185-198 (1986).

DOI: 10.1016/S0022-3093(86)80078-3

[9] Brinker C. J., Keefer K. D., Schaefer D. W., Assink R. A., Kay B. D., Ashley C. S.: Sol-gel transition in simple silicates II. Journal of Non-Crystalline Solids, 63, 45-59 (1984). DOI: 10.1016/0022-3093(84)90385-5

[10] Yuan Q. W., Mark J. E.: Reinforcement of poly (dimethylsiloxane) networks by blended and in-situ generated silica fillers having various sizes, size distributions, and modified surfaces. Macromolecular Chemistry and Physics, 200, 206-220 (1999).

DOI: 10.1002/(SICI)1521-3935(19990101)200:1<206 $\because$ AID-MACP206>3.0.CO;2-S

[11] Kumudinie C., Mark J. E.: Tearing energies for in-situ reinforced poly(dimethylsiloxane) networks. Materials Science and Engineering C, 11, 61-66 (2000). DOI: 10.1016/S0928-4931(00)00143-0

[12] Mark J. E., Ning Y-P.: Effects of ethylamine catalyst concentration in the precipitation of reinforcing silica filler in an elastomeric network. Polymer Bulletin, 12, 413-417 (1984). DOI: $10.1007 / \mathrm{BF} 00255427$
[13] McCarthy D. W., Mark J. E., Schaefer D. W.: Synthesis, structure, and properties of hybrid organic-inorganic composites based on polysiloxanes. I. Poly (dimethylsiloxane) elastomers containing silica. Journal of Polymer Science Part B: Polymer Physics, 36, 1167-1189 (1998).

DOI: $10.1002 /($ SICI)1099-0488(199805)36:7<1167:: AID-POLB7>3.0.CO;2-R

[14] Rajan G. S., Sur G. S., Mark J. E., Schaefer D. W., Beaucage G.: Preparation and characterization of some unusually transparent poly(dimethylsiloxane) nanocomposites. Journal of Polymer Science Part B: Polymer Physics, 41, 1897-1901 (2003).

DOI: $10.1002 /$ polb.10565

[15] Bokobza L., Diop A.: Reinforcement of poly(dimethylsiloxane) by sol-gel in situ generated silica and titania particles. Express Polymer Letters, 4, 355-363 (2010). DOI: $10.3144 /$ expresspolymlett.2010.45

[16] Mark J. E., Ning Y-P., Jiang C-Y., Tang M. Y., Roth W. C.: Electron microscopy of elastomers containing insitu precipitated silica. Polymer, 26, 2069-2072 (1985). DOI: 10.1016/0032-3861(85)90189-2

[17] Dewimille L., Bresson B., Bokobza L.: Synthesis, structure and morphology of poly(dimethylsiloxane) networks filled with in situ generated silica particles. Polymer, 46, 4135-4143 (2005).

DOI: $10.1016 /$ j.polymer.2005.02.049

[18] Ning Y. P., Tang M. Y., Jiang C. Y., Mark J. E., Roth W. C.: Particle sizes of reinforcing silica precipitated into elastomeric networks. Journal of Applied Polymer Science, 29, 3209-3212 (1984).

DOI: 10.1002/app.1984.070291022

[19] Bale H. D., Schmidt P. W.: Small-angle X-ray-scattering investigation of submicroscopic porosity with fractal properties. Physical Review Letters, 53, 596599 (1984).

DOI: 10.1103/PhysRevLett.53.596

[20] Fragiadakis D., Pissis P., Bokobza L.: Glass transition and molecular dynamics in poly(dimethylsiloxane)/silica nanocomposites. Polymer, 46, 6001-6008 (2005). DOI: $10.1016 /$ j.polymer.2005.05.080

[21] Fragiadakis D., Pissis P., Bokobza L.: Modified chain dynamics in poly(dimethylsiloxane)/silica nanocomposites. Journal of Non-Crystalline Solids, 352, 49694972 (2006).

DOI: $10.1016 /$ j.jnoncrysol.2006.02.159

[22] Fragiadakis D., Pissis P.: Glass transition and segmental dynamics in poly(dimethylsiloxane)/silica nanocomposites studied by various techniques. Journal of Non-Crystalline Solids, 353, 4344-4352 (2007). DOI: $10.1016 /$ j.jnoncrysol.2007.05.183

[23] Hernández J. C. R., Pradas M. M., Ribelles J.: Properties of poly(2-hydroxyethyl acrylate)-silica nanocomposites obtained by the sol-gel process. Journal of Non-Crystalline Solids, 354, 1900-1908 (2008). DOI: $\underline{10.1016 / \text { j.jnoncrysol.2007.10.016 }}$ 
[24] Yue Y. L., Zhang H., Zhang Z., Chen Y. F.: Tensile properties of fumed silica filled polydimethylsiloxane networks. Composites Part A: Applied Science and Manufacturing, in press (2013).

DOI: 10.1016/j.compositesa.2013.06.016

[25] Llorente M. A., Andrady A. L., Mark J. E.: Model networks of end-linked polydimethylsiloxane chains. XI. Use of very short network chains to improve ultimate properties. Journal of Polymer Science: Polymer Physics Edition, 19, 621-630 (1981). DOI: $10.1002 /$ pol.1981.180190406

[26] Mark J. E., Sullivan J. L.: Model networks of endlinked polydimethylsiloxane chains. I. Comparisons between experimental and theoretical values of the elastic modulus and the equilibrium degree of swelling. Journal of Chemical Physics, 66, 1006-1011 (1977). DOI: $10.1063 / 1.434056$

[27] Mark J. E.: The constants $2 C_{1}$ and $2 C_{2}$ in phenomenological elasticity theory and their dependence on experimental variables. Rubber Chemistry and Technology, 48, 495-512 (1975). DOI: $10.5254 / 1.3547463$

[28] Craievich A. F.: Synchrotron SAXS studies of nanostructured materials and colloidal solutions. A review. Materials Research, 5, 1-11 (2002). DOI: 10.1590/S1516-14392002000100002

[29] Young R. J., Al-Khudhairy D. H. A., Thomas A. G.: Characterization of filled rubbers using small-angle Xray scattering. Journal of Materials Science, 21, 12111218 (1986).

DOI: $10.1007 / \mathrm{BF} 00553253$

[30] Hammersley A., Svensson S., Hanfland M., Fitch A., Hausermann D.: Two-dimensional detector software: From real detector to idealised image or two-theta scan. International Journal of High Pressure Research, 14, 235-248 (1996).

DOI: $\underline{10.1080 / 08957959608201408}$
[31] Andrady A. L., Llorente M. A., Mark J. E.: Model networks of end-linked polydimethylsiloxane chains. VII. Networks designed to demonstrate non-Gaussian effects related to limited chain extensibility. Journal of Chemical Physics, 72, 2282-2290 (1980). DOI: $10.1063 / 1.439472$

[32] Smith T. L., Haidar B., Hedrick J. L.: Origin of the self-reinforcement in PDMS bimodal networks. Rubber Chemistry and Technology, 63, 256-264 (1990). DOI: $10.5254 / 1.3538256$

[33] McCarthy D. W., Mark J. E., Clarson S. J., Schaefer D. W.: Synthesis, structure, and properties of hybrid organic-inorganic composites based on polysiloxanes. II. Comparisons between poly(methylphenylsiloxane) and poly(dimethylsiloxane), and between titania and silica. Journal of Polymer Science Part B: Polymer Physics, 36, 1191-1200 (1998).

DOI: 10.1002/(SICI)1099-0488(199805)36:7<1191:: AID-POLB8>3.0.CO;2-X

[34] Konarev P. V., Volkov V. V., Sokolova A. V., Koch M. H. J., Svergun D. I.: PRIMUS: a Windows PC-based system for small-angle scattering data analysis. Journal of Applied Crystallography, 36, 1277-1282 (2003). DOI: $10.1107 / \mathrm{S} 0021889803012779$

[35] Chen K. C., Tsuchiya T., Mackenzie J. D.: Sol-gel processing of silica: I. The role of the starting compounds. Journal of Non-Crystalline Solids, 81, 227-237 (1986). DOI: 10.1016/0022-3093(86)90272-3

[36] Pouxviel J. C., Boilot J. P., Beloeil J. C., Lallemand J. Y.: NMR study of the sol/gel polymerization. Journal of Non-Crystalline Solids, 89, 345-360 (1987).

DOI: $10.1016 / \mathrm{S} 0022-3093(87) 80277-6$

[37] Brinker C. J., Keefer K. D., Schaefer D. W., Ashley C. S.: Sol-gel transition in simple silicates. Journal of Non-Crystalline Solids, 48, 47-64 (1982). DOI: 10.1016/0022-3093(82)90245-9 